\title{
Sectoral Effects of Public Policy Reforms in Benin: Case of the Health System
}

\author{
Prince Comlan Eugene Adjovi ${ }^{1,}$, , Ibrahima Thiam ${ }^{1}$, Fabienne Fecher ${ }^{2}$ \\ ${ }^{1}$ Thies Applied Economics and Finance Research Centre, Department of Economics and Social Science, University of Thies, Thies, Senegal \\ ${ }^{2}$ Faculty of Social Sciences, University of Liège, Liège, Belgium
}

Email address:

pacedimass@gmail.com (P. C. E. Adjovi), ithiam@univ-thies.sn (I. Thiam), ffecher@uliege.be (F. Fecher)

${ }^{*}$ Corresponding author

\section{To cite this article:}

Prince Comlan Eugene Adjovi, Ibrahima Thiam, Fabienne Fecher. Sectoral Effects of Public Policy Reforms in Benin: Case of the Health System. International Journal of Health Economics and Policy. Vol. 5, No. 3, 2020, pp. 54-62. doi: 10.11648/j.hep.20200503.12

Received: August 10, 2020; Accepted: August 31, 2020; Published: September 10, 2020

\begin{abstract}
The closure of illegal health facilities and the elimination of dual membership of health professionals have been part of health reforms since 2016 in Benin. This research was intended to deeply analyze the immediate effects of new reforms in hospitals and assess governance implications. Methods: The research was a retrospective analysis conducted by a mixed method, using both qualitative and quantitative primary data from three public hospitals and one confessional, from the national public health office and of administration and finances office. Health human resources and their complaints, attendance at health care units, monthly hospital revenues and corrupt practices were used as variables. The research covered the first semesters of 2018 and 2019. The sample was made by reasoned choice. Results: Attendance increased at public hospitals from $12 \%$ to $80 \%$ and their monthly revenues up to $200 \%$ in 2019 and hospitals staffs were present with overload of work. The private hospital suffered a drop of- $33 \%$ in attendance and-5\% in monthly revenues, followed by a staff shortage. Discussion: The reforms have given confidence to public health facilities users and revealed the weak hospitals capacity and difficulties in managing patient flows and staff. Conclusion: There's a start in improving practices for better hospital performance. Government involvement and technical platforms strengthening are crucial for sustainable results and private hospitals must recruit their own staff.
\end{abstract}

Keywords: Governance, Performance, Hospital, Reforms, Health System

\section{Introduction}

The spatial distribution of hospitals of Benin's health system is pyramidal [1]. This organization is inspired by the health district model seen as relevant and robust [2-4] as recommended by the world bank. This pyramidal distribution is characterized by a large number of hospitals at the peripheral level that offer mainly general medicine, and a small number of hospitals at the central level that include a larger set of special health care. At the peripheral level, these are zone hospitals, equivalent to district hospitals, which constitute the first referral hospitals. At the intermediate level, there are departmental hospitals to receive referred patients in second instance, normally coming from zone hospitals; then at the central level, the national or central hospitals which receive referrals as a last resort, therefore the third referral level [5].
With the various reforms undertaken in the health sector since 2001 and despite a health infrastructure coverage of $95 \%$, the attendance rate is estimated at $45 \%$ [6] and health indicators have deteriorated over the past ten years. This deterioration is reflected in infant, child, and neonatal mortality rates, respectively dropping from 70 deaths per thousand live births, 42 deaths per thousand and 23 deaths per thousand in 2011 to 96 per thousand, 55 per thousand and 30 per thousand births alive in 2018 [7].

In this context the deterioration of health indicators in Benin, hospitals performance, particularly the district's, is pointed out as an important determinant of these results [8]. Through the report of the Technical Commission in charge of reforms in the health sector, poor governance in the sector 
partly explains the weak hospital performance. The lack of control over opening and exercising health activities in private conditions, the illicit sale of drugs, the abandonment of public services, the diversion of patients and other corruption practices are all grievances that are formulated against health structures in Benin [9]. In this context, hospital management appears to be failing [10]. Since the submission of the report of the technical commission in June 2017 and in the current environment of public administration reforms, new initiatives to reorganize the health sector have led to the prohibition of the illicit sale of drugs with the destruction of illegal sources of supply in accordance with the Cotonou Convention 2009 appeal on the fight against counterfeit medicines [11], the closure of illegal health centers as recommended by the Technical Commission. In such an environment where the State alone cannot meet all the needs of the populations, private health services, even illegally installed, could have been useful to patients. Unfortunately, in this context of illegal installation and exercise of the health profession, these health centers could also be considered as major contributors to the deterioration of health indicators [12]. To fully understand these major differences, analysis of policy decisions is necessary [13].

Faced with the shortage of health personnel [9], the unequal distribution of public health facilities and the increasingly growing needs of the populations, the analysis of the effects that would result from the closure of private and illegally installed health facilities, of the prohibition of exercising the health professions in both the public and private sectors by health personnel, is highly relevant. The objective of this research is to analyze these governance issues by measuring the impact of the recent reforms of the Beninese health system. It is part of a global research evaluating the performance of regional hospitals. It aims in particular to measure the first results of a vast project of reforms underway within the Beninese health system. The structure of this article is presented as follows: the first section is devoted to health system reforms; the second section presents the methodology and the third section presents and analyzes the main results.

\subsection{Health System and Hospital Reforms and Good Governance Challenges}

The reforms undertaken since 2016 mainly concern the reorganization and consolidation of the health system. Interventions are much more based on the components of health human resources, drug supply, service delivery and governance referring to the six pillars of health system strengthening [14]. In fact, in the face of the crises that the health systems of several countries have encountered over the years, a common response has been the adoption of good governance measures. They ranged from the closure of certain hospitals (Canada), to the affermage of others, from the reduction in the number of beds in certain hospitals to the merger of other hospitals (Sweden) and the transformation of some public hospitals into public limited companies (Germany and Portugal) [15]. They appear as forms of new governance to relaunch health systems in the face of various challenges, particularly those of effectiveness and efficiency. Governance is an objective notion comprising complex mechanisms, processes, relationships and institutions through which citizens and groups articulate their interests, exercise their rights and fulfill their obligations and to which they turn in order to resolve their differences $[16,17]$. In the health sector, actors have too much power and very different interests when they must work to preserve their only common interest which is "the health capital of populations" [18]. These health workers set up "Local Professional Cultures" [19]. They are made up of corruption, illicit sales of drugs, and embezzlement of patients. These ailments are not new in the Beninese health system [9].

\subsection{In Benin, the Private Sector Is an Important Actor of the Health System}

The private health sector contributions are relevant and important to achieve public health goals [20]. But the challenge remains the quality of health services provided to the population. In Benin, many clinics or private health facilities weren't authorized and sometime owned by non-qualified health workers [12]. It confirms that the robustness of the private sector in health is affected by a poor regulation or an ineffective court system, accountability, government effectiveness and control of corruption [21]. In the recent past, drugs were sold on the sly, in defiance of regulation. The health workers organized illegal drugs sales within hospitals without respecting the organization of hospital services. Some abandon public services to devote themselves to private services. They caused long appointments for consultations and patient care. Also, corruptive practices are organized to extort funds from patients. Corruption is explained as the use of public office or the sale of government property for private or personal gain [21-23] and violate patient's right to benefit from public policy entitled on them.

There will then be a need for strong interventions of good governance which covers "all the organizational and institutional mechanisms capable of delimiting the powers and influencing the decisions of managers, in other words, which "govern" their attitudes and define their discretionary space" [24]. The government should set up some priorities for "a clear definition of political orientations and plans for collaboration with the private sector and the strengthening of basic regulatory functions for better collaboration" [20].

Considering the scarcity of resources, the requirement for efficiency and the need to ensure universal health coverage for the populations, good governance practices come into the management game and therefore into the management of the hospital. These governance practices require in particular to remind all the actors that they are united around a "knot of contracts" and that each one has the obligation to respect the work commitments with "the existence of a power of authority, and the recognition that hospital is a hierarchical 
organization" [25]. In 2019, The government of Benin has thus taken fundamental actions, some of which boil down to the prohibition of the illicit sale of drugs, the accumulation of the exercise of the health profession by professionals between the public sector and the private sector, the obligation to respect contractual commitments, the closure of private health facilities illegally installed and the withdrawal of licenses for private practice renewed in accordance with the conditions of the new reforms.

\section{Brief summary of reforms in the health sector in Benin}

The health sector reform included in the government action program 2016-2021 revolves around three axes: (1) improving governance and resource management in the sector health (2) universal access to health services and better quality of care (3) strengthening the partnership for health [26]. Based on that program, a set of interventions has been implemented in terms of reforms. Among these interventions, it is important to mention a few. The method of appointing hospital directors has changed based on technical criteria and not on political as recommended a study on universal health coverage in francophone Africa towards learning organization [27]. They are appointed after passing a recruitment test. The hourly regime for health personnel has been revised to facilitate continuity of service. The workload is re-fixed and overtaking gives the right to a bonus as motivation. The texts on the opening and operation of private health centers and private clientele exercise have come into force. With the decree $n^{\circ} 2018-283$ of July 4th 2018, the dual membership of the medical and paramedical professions is prohibited. Authorizations to open private health care practices and clinics are suspended. In fact, an earlier research showed that of "231 private health practices surveyed, only 28 (12 percent) were authorized"[28] and a prior assessment of private health providers recommended the growth of the formal private health provider sector by streamlining registration and licensing processes for businesses and supporting provider networks [29]. This made it possible to close the illegally installed health facilities and to give back the authorizations to the actors who meet the legal conditions [30].

The sites and networks of illicit sales of fake medicines have been denied. The actors who operate in this sector have been arrested and handed over to justice, and the authorizations to import and distribute medicines have been canceled and renewed only for those who fulfill conditions. The sale of drugs in pharmacies is conditioned by the presentation of prescription duly signed by the health worker, especially for certain drugs [31].

These various measures seem to respond to the recommendations of the 2016 Commission responsible for reforms in the health sector, which stem from an inclusive and objective assessment [9]. The correct implementation of the new measures is assumed with multisector collaboration involving the security forces and the justice sector. These two stakeholders help strengthen the control and judgment of offenders and through the enforcement of laws.

With these new reforms, the health worker recruited to work in public health facilities no longer has the possibility of easily working in the private sector. He cannot be the owner of a health center or a private health facility. Medicines, too, are no longer provided by everyone without required professional conditions sanctioned by prior authorization from the state authority.

This research aimed to highlight the immediate effects of these reforms implemented within the health system on hospitals as suggested Benmarhnia and Fuller on health program effect evaluation [32] and to assess their implications in terms of governance.

\section{Research Materials and Methods}

\subsection{Research Framework}

This research has been conducted in Benin Republic. It is a French speaking country located in West Africa covering an area of $114,763 \mathrm{~km} 2$ with an estimated population of $11,884,127$ inhabitants according 2019 population projections [7, 33]. Precisely the research took place in Atlantique department subdivided in height districts and Littoral department with its only one district territories. These are two departments with a surface of $3312 \mathrm{~km}^{2}$ containing 2,077,241 inhabitants representing $17.48 \%$ of Benin population [33].

\subsection{Type, Period and Population of Study}

This paper is the result of a study carried out by a mixed (qualitative and quantitative) retrospective and transversal, analytical method. It covers the first semesters of 2018 and 2019. We used the reflexive group model [34]. This model suggest the use of the same group before and after the intervention. In fact the research has been conducted on a group of hospitals without the reform in the first semester of the year 2018 and the same group has been submitted on the research process on the first semester 2019 based on data related to the new reform implemented toward universal health coverage policy.

\subsection{Research Variables}

Five different variables were used in this research. There are namely health human resources (HHR), attendance at care units, monthly hospital revenues, complaints from health human resources and corruption's practices.

HHR analyzed in this work are generalist physicians, nurses, midwives, laboratory technicians, anesthesiologistsresuscitators, gynecologists, surgeons and other caregivers.

Additional variables are used to document the problematic of private health facilities. There are Number of private health facilities before and after the application of decree $n^{\circ}$ 2018-342 of July 25, 2018, number of qualified health workers who have resigned from the public service and the monitoring and evaluation scheme. 


\subsection{Data Collection and Tools}

The research involved primary data. For data collection a questionnaire incorporating a statistical data collection grid has been administered directly to respondents completed by the statistical managers in four district hospitals which are the statistical units of the study. These sources are associated with interviews with some health workers and some management staff. The data collected from hospitals is supplemented by other data collected from the national public health department and the human resources department in the Ministry of Health. They concern the closed illegal private health facilities, the number of new authorizations granted and the number of health professionals who have left the public sector for the private sector.

\subsection{Sampling}

The study sample is constructed in a reasoned fashion. It includes four district and similar hospitals (three public and one private) from the Atlantique and Littoral departments, out of thirty district hospitals available in Benin. The national health system is fulfilled of 1117 health facilities all categories combined, included 59 hospitals and 30 district hospitals [35] in 30 health districts out of 34 required. The research is focused in two departments out of 12 departments for the whole country.

For confidentiality and ethical reasons, hospitals has been renamed as follow Hpublic1, 2 and 3 to identify the three public hospitals and Hprivate for the private hospital.

\subsection{Ethical Clearance}

Informed consent of the various actors surveyed for the research was obtained. We ensured that anonymity and confidentiality were respected.

\section{Findings and Discussions}

\subsection{The Effects of Reform on the Private Health Sector}

The fundamental of the reform is the law $n^{\circ} 97-020$ of June 17, 1997 setting the conditions for the practice of medical and paramedical professions in private clients. That law set that this practice is conditioning by issuance of authorization from the Ministry of Health. Public service workers are not authorized to do so [36].

The reform recalled those conditions and fixed as essential conditions to obtain an authorization to practice as private health services providers.

The research work shows that before the decree of July 25 , 2018 and with non-compliance with regulatory texts, there were 2,614 private health establishments, according to a census carried out in December 2017 (National Public Health Directorate, 2020).

Since the reform is been applied, all these authorizations were suspended and new ones were issued for the opening of 918 private health facilities and 13 qualified health workers resigned to work in the private sector.

\subsection{The Effects of Reform on Activities Indicators}

The data collected at the level of the four hospitals show the use of a variety of health professional statuses and the existence of shortages in nurse's staff notwithstanding the permanent agents who are recruited such as State officials and State Contractual Agents in the public hospitals as showed an evaluation of health workers availability and capacity for $\mathrm{UHC}^{1}$ in $\mathrm{MCH}^{2}$ services in Benin [30] and permanent contractual agents in the private and associative hospital. To remedy this deficit, the three public hospitals use service contracts whereby providers are paid in proportion to the time spent in these services while the private and associative hospital uses service contracts with fixed monthly remuneration. This use of hospitals contractual staff represents more than $40 \%$ in the two university hospitals (Hpublic $^{3}$ and Hpublic $3^{1}$ ), more than $25 \%$ at the Hpublic $1^{1}$ and less than $15 \%$ in Hprivate ${ }^{4}$. This situation relates more to medical staff and especially specialist doctors grouped together under the name of other contractual caregivers than to paramedical staff (see Figure 1 below).

In addition, it is observed that the staff numbers of the four hospitals have experienced disruption with the intervention of new measures to reorganize the practice of the profession in the Benin health system. Figures 2, 3, 4 and 5 show in detail the variations in staff number (histograms: blue for 2018 and red histograms for 2019). They are observed through an increase, for most hospitals, in the number of general practitioners except Hpublic3. The Hprivate (Figure 5) has doubled its staff of general practitioners, increased the number of gynecologists by recruiting contractual workers, while the group of other caregivers made up of specialist physicians saw its workforce reduced by 5\%. Apart from Hpublic3 (Figure 4), staff statistics have remained stable in other hospitals.

Looking closely at the different types of health professionals used at the Hprivate, a confessional hospital, it would be tempting to say that the doctors who served as providers in this health facility are largely agents of public hospitals In fact, before the reform, the public health workers abandoned public health facilities in favor of private health facilities for jobs Also, public hospitals attendance increased in the first half of 2019 compared to the same period in 2018, while attendance fell by $25 \%$ on average in surgery, medicine and maternity departments. This trend can be seen in Figure 4 which shows the change in attendance in the medical, pediatric, maternity and surgical units of the hospitals obtained in the study. The increase observed in the public services is not only due to the prohibition to combine the exercise of the health profession between the public and private sectors. The closure of clandestine and / or illegal health facilities could also be obvious causes.

\footnotetext{
${ }^{1}$ Universal Health Coverage.

${ }^{2}$ Maternal and Child Health.

${ }^{3}$ Hpublic $=$ Public district hospitals.

${ }^{4}$ Hprivate associative hospital involved in the research.
} 


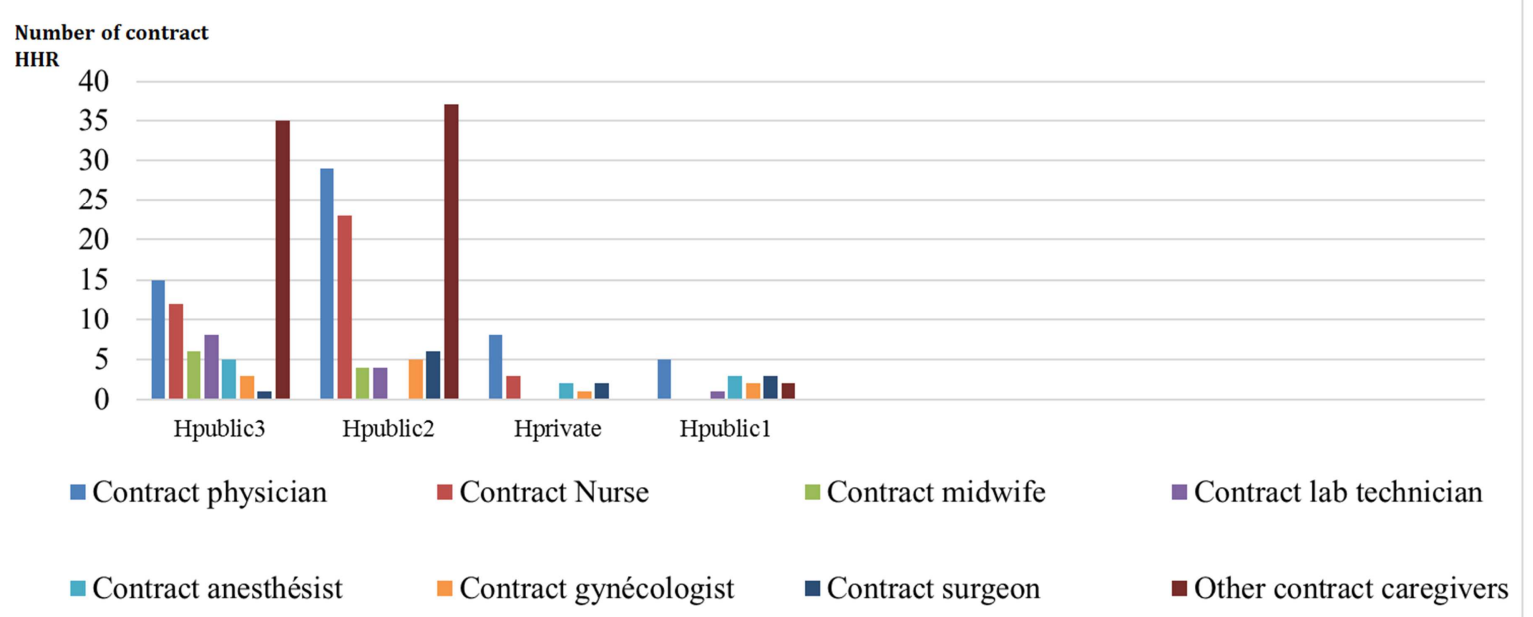

Source: Authors based on raw data collected in hospitals.

Figure 1. Number of health workers recruited by hospitals through service contracts 2018.

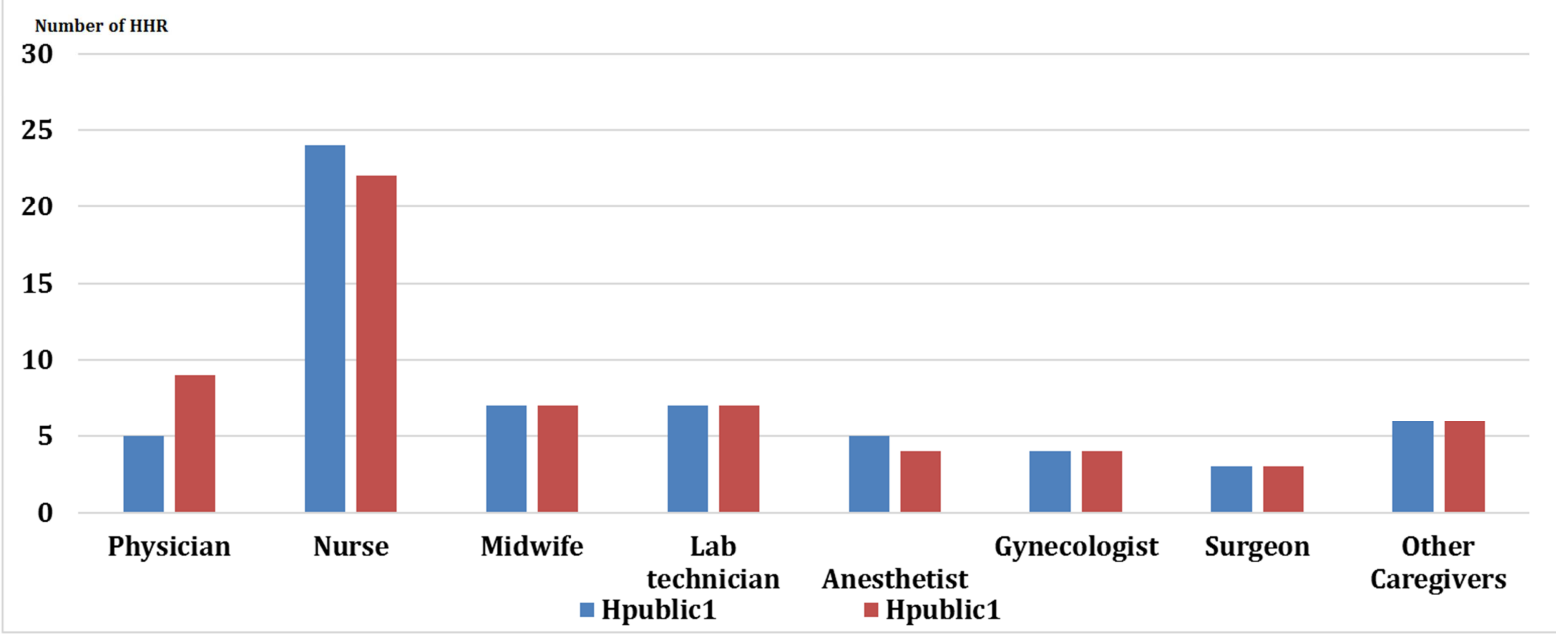

Figure 2. Evolution of the health workforce between 2018 and 2019 in Hpublic1.

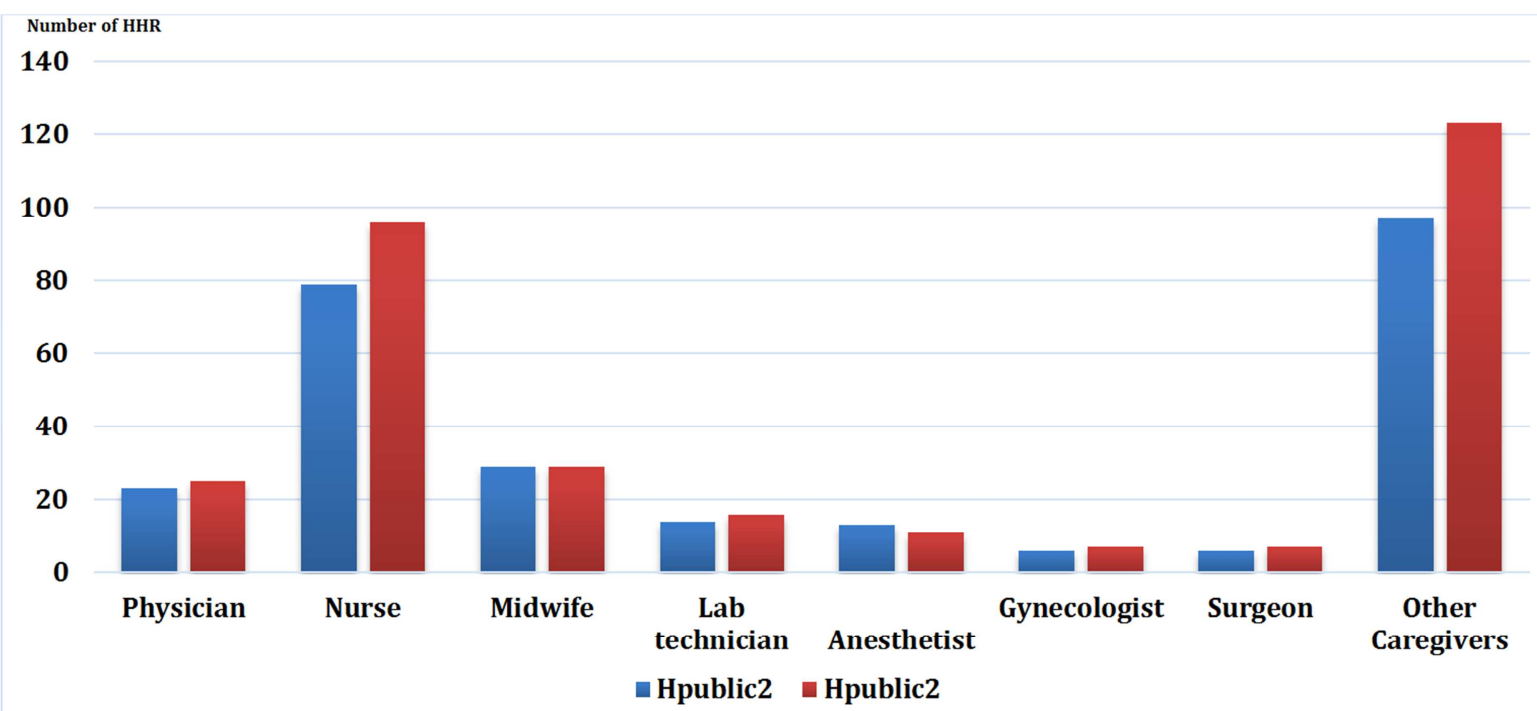

Figure 3. Evolution of the health workforce between 2018 and 2019 in Hpublic2. 


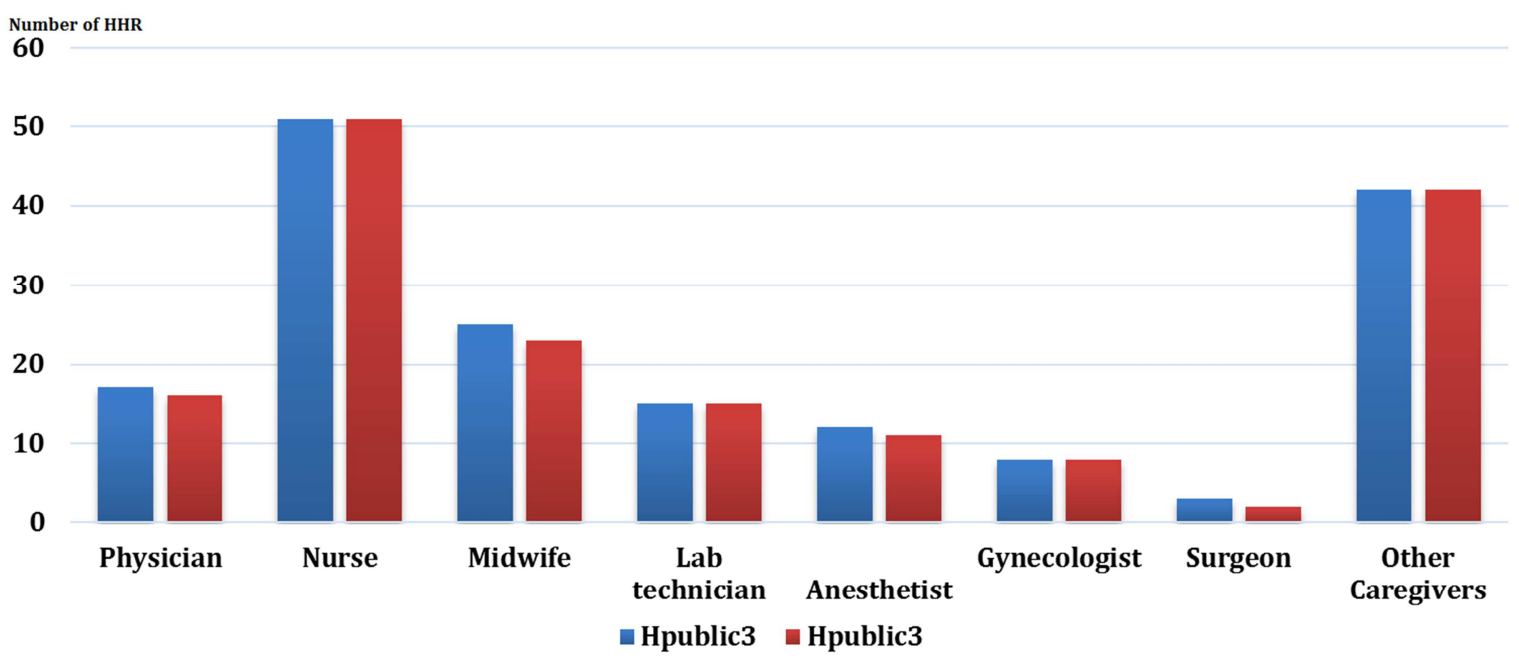

Figure 4. Evolution of the health workforce between 2018 and 2019 in Hpublic3.

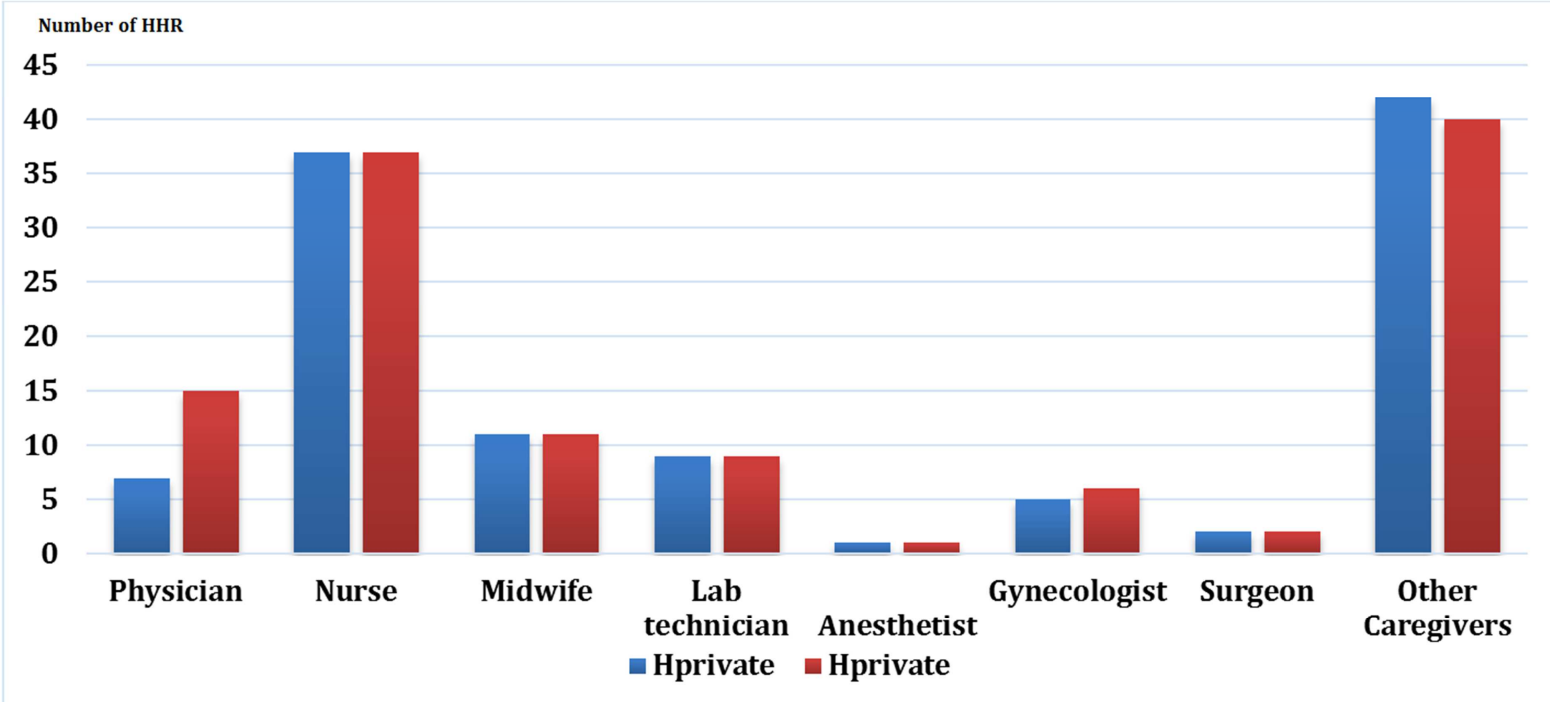

Source: Authors based on raw data collected in hospitals

Figure 5. Evolution of the health workforce between 2018 and 2019 in Hprivate.

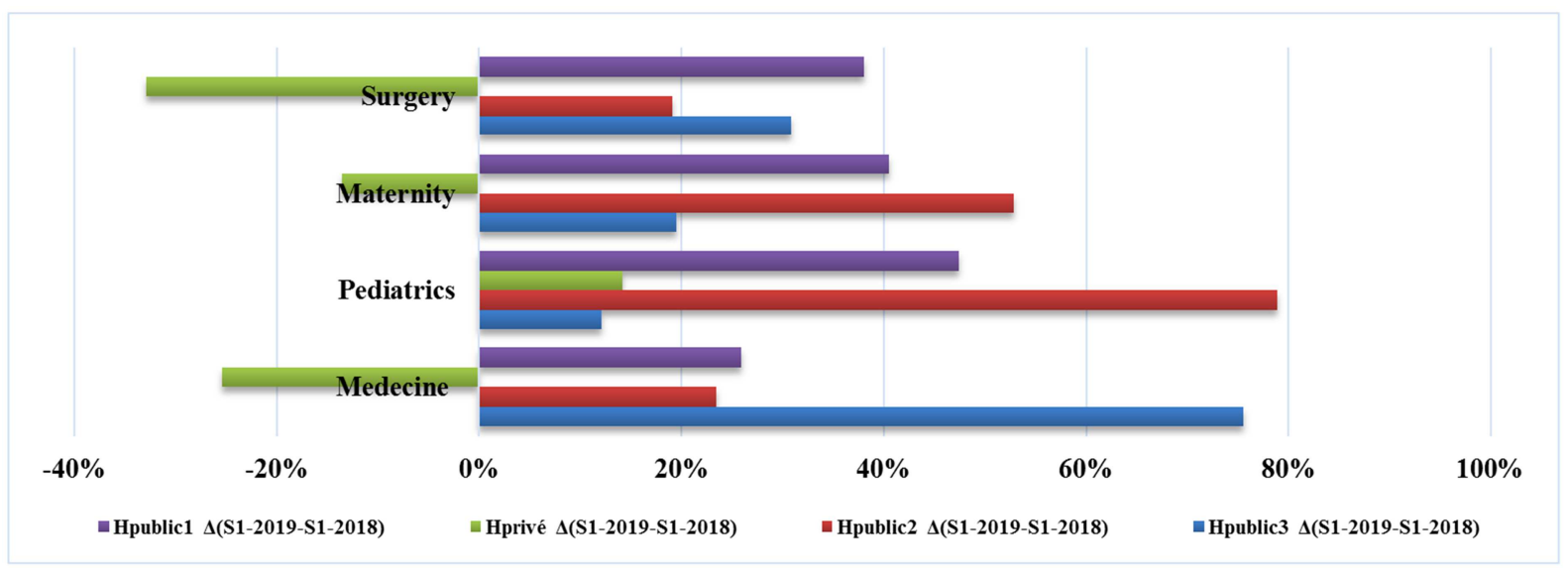

Source: Authors based on raw data collected in hospitals.

Figure 6. Comparative evolution of hospital visits in the first semesters of 2018 and 2019. 
This increase in attendance has led to an increase in revenues ranging from $12 \%$ to nearly $200 \%$ over the course of one month at the Hpublic1 over the period of the first half of 2019 compared to the same period of the year 2018. While at the Hprivate, which is experiencing a drop in the attendance of healthcare units, it is been observed, on the other hand, declining results in revenues ranging from $12 \%$ to be in deficit with a difference of $-5 \%$ in the last month of the first half of 2019.

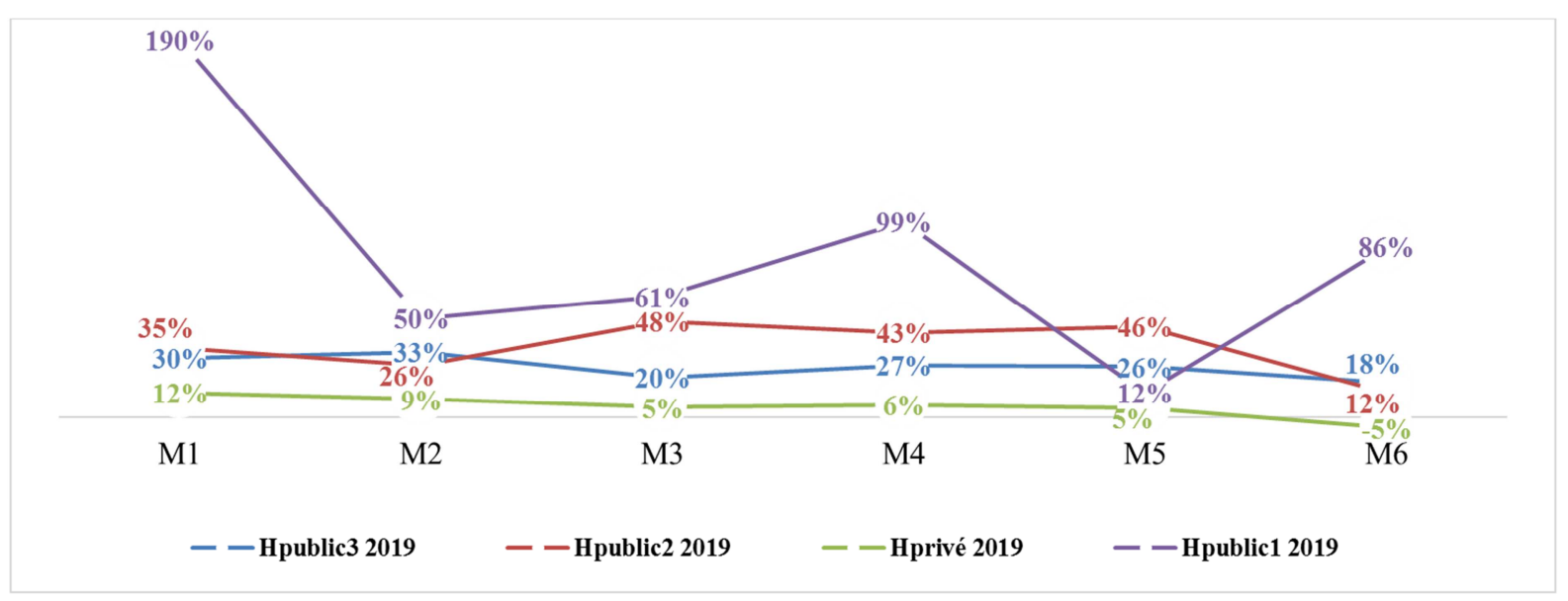

Source: Author's calculation based on raw data collected in hospitals.

Figure 7. Comparative evolution of income in the 1st semesters of 2018 and 2019.

In addition to the improvement in service attendance and revenues in these different public health facilities, other changes have been observed. These are the practices of diverting patients to private structures (legal or illegal) owned by certain public officials, the illicit sale of drugs in hospitals, the payment of bribes and other acts of corruption, which have made for a long time the nest in the economic and social underperformance of these public hospitals and apparently less critical in the confessional private hospital, which seem to have declined according to the managers of these hospitals. Another observation in favor of these reforms is the effective presence of health workers at the posts. This observation is made in all public hospitals and allows the management team to enforce the availability and continuity of care. It suggests that public hospitals are operating at full capacity and have positive operating results, unlike private and associative hospitals. This change stems from the respect of the new orientations by the health personnel working in these different public hospitals. With these changes, caregivers complain of overwork as well as a lack of motivation. These trends have been observed in other contexts "where policies to regulate and reduce spending have gone too far and have had negative effects on the performance of health services and hospitals" [38]. Such regulation in England and Canada was mainly based on a restructuring policy which was characterized by the closure of many hospitals and staff reductions. These reforms have generally led to a loss of performance and quality of care $[14,15,39]$. The present results raise fears of a potential deterioration in the quality of care which has already been observed in those countries which have implemented these drastic reforms as they are currently taking place in the Benin health system. These fears are linked to the overuse of equipment and materials that can be depreciated early, to the overload of hospital staff and the risk that health funding will not increase.

\section{Conclusion}

Since 2016, the Beninese health system has been living a new era animated by structural and organizational reforms with the aim of responding to the major challenges imposed by the epidemiological transition, the scarcity of resources, and poor performance in the health sector. These reforms, long awaited in the sector, are now being carried out from the perspective of governance. It appeared opportune to carry out an evaluation in order to identify the first results that could help to better assess the relevance of the interventions that are being carried out and, as far as possible, allow the necessary adjustments to be made. These initial results, resulting in increased use of services, increased revenues, and the effective presence of nursing staff at posts, are generally encouraging. It appears clear that the involvement of the state authority and the control of the management of the health sector were necessary for a good implementation and the respect of the organizational standards.

The modus operandi in the sector seemed to camouflage the real needs in the public sector, which is penalized internally by its leaders.

\section{Recommendations}

To maintain these various results in the logic of lasting improvement, it will be necessary to pay particular attention to the needs of the health workers who lead it. There are problems of the quality of care, the financial access of users of health services, the depreciation of materials and equipment and the adequate funding of hospitals. It will also be necessary to think about giving the users of health services 
confidence in the health centers which will serve as filters while respecting the principles of reference against reference. This will have the advantage of not devoting resources at the hospital level to simple cases or trivial ailments that can be managed in health centers. Another is the improvement in the performance of the health system, accelerating the march towards universal health coverage.

\section{Authors Contributions}

The research was designed and carried out by all authors. The questionnaire was developed by Ibrahima Thiam and Prince Comlan Eugène Adjovi, reviewed and approved by Fabienne Fecher. Prince Comlan Eugène Adjovi collected, cleared and processed the data with a first draft of analysis. This analysis was reviewed and finalized by Ibrahima Thiam and Fabienne Fecher. The manuscript was consolidated and edited by Prince Comlan Eugène ADJOVI then read and approved by Ibrahima Thiam and Fabienne Fecher. All the authors have read and approved the various drafts and the final version of the manuscript.

\section{Conflict of Interest Statement}

The authors declare that they have no conflict of interest in the context of this research.

\section{Acknowledgements}

The authors would like to thank all the managers and health personnel at the level of the zone hospitals, the authorities at the level of the Ministry of Health and all actors who supported this research. The authors also thank Dr Sam Wanilo Lesfranc AGBAHOUNGBA (PhD CREFAT/ University of Thies, Senegal), André MBOULE (PhD Candidate at Atlantic International University, Honolulu, USA) and Dr Frieda VANDENINDEN (PhD University of Liège, Faculty of Social Sciences, Belgium) for their contribution to improving the quality of the manuscript.

\section{References}

[1] L. Salami, E.-M. Ouendo, and B. Fayomi, "Quality of the Health Intervention Information and Monitoring System in Results-Based Funding Areas in 2014 in Benin," Pan Afr Med J, Vol. 28, Nov. 2017, doi: 10.11604/pamj.2017.28.257.10967.

[2] D. Grodos and R. Tonglet, "Mastering a coherent and efficient health space in sub-Saharan African cities: the health district to be tested," Tropical Medicine - International Health, 7, No. 11, p. 977-992, 2002, doi: 10.1046/j.1365-3156.2002.00925.xi.

[3] J.-D. Rainhorn and M.-J. Burnier, Ed., Health at Market Risk: Uncertainties at the Dawn of the 21st Century. Geneva: Graduate Institute Publications, 2017.

[4] P. Fournier, S. Haddad, and P. Mantoura, "Health System Reforms in Developing Countries: The Irresistible Grip of International Agencies and the Dangers of Single Thinking," in Health at Market Risk: Uncertainties at the Dawn of the 21st Century, J.-D. Rainhorn and M.-J. Burnier, Geneva: Graduate Institute Publications, 2017, 71-84.

[5] MoH, "Health Statistics Yearbook 2016," 165, 2016.

[6] MoH, "Health Statistics Directory." 2017.

[7] INSAE, MPD, "Demo Figureic and Health Survey in Benin," INSAE, Benin, Fifth, 2019.

[8] Y. G. Ahanhanzo, L. S. L. Ouédraogo, and J. Saizonou, "Performance of a Health Zone Hospital in Benin: An Example of Evaluation Model," Pan Afr Med J, 18, May 2014, doi: 10.11604/pamj.2014.18.63.3465.

[9] CTRSS, "Summary Report of the Technical Commission in charge of Reforms in the Health Sector.pdf," Benin, 2017.

[10] Zongo M., Capochichi J., Gandaho P., Takpara I., and Coppieters Y., "Managerial Management of Hospital Structures in Benin," 2009.

[11] Chirac Foundation, "The Cotonou Appeal, October 12, 2009." 2009, Consulted on: August 15, 2019. [Online]. Available on: https://www.fondationchirac.eu/prevention-conflits/acces-auxmedicaments/mobilisation-internationale-contre-trafic-fauxmedicaments/.

[12] CTRSS, "RAPPORT GENERAL CTRSS BÉNIN 2017.PDF". 2017.

[13] WHO, Ed., Funding health systems: the path to universal coverage. Geneva, 2010.

[14] D. B. Reissman, P. Orris, R. Lacey, and D. E. Hartman, "Downsizing, role demands, and job stress", J. Occup. Environ. Med., vol. 41, no 4, p. 289-293, avr. 1999, doi: 10.1097/00043764-199904000-00011.

[15] Mordelet Patrick, Hospital Governance and the Health Systems Crisis. School of Higher Studies in Public Health, 2006.

[16] M. Razafindrakoto and F. Roubaud, "Governance Indicators: Relevance, Use and Limits," 31, 2007.

[17] S. Siddiqi and coll., "Framework for assessing governance of the health system in developing countries: Gateway to good governance", Health Policy, vol. 90, no 1, p. 13-25, apr. 2009, doi: 10.1016/j.healthpol.2008.08.005.

[18] G. Charreaux, "Hospital Governance: Some Reflections From Corporate Governance," FARGO Paper 1100705.

[19] J.-P. O. de Sardan, "The midwife and the customs officer. Local occupational cultures and privatized bureaucratic culture in West Africa," Other, 20, No. 4, 61, 2001, doi: 10.3917/autr.020.0061.

[20] Sarrah Bennett, Kara Hanson, Patrick Kadama, and Dominic Montagu, "WORK WITH THE PRIVE SECTOR FOR REALISER THE PUBLIC HEALTH OBJECTIVES," Geneva, 2005.

[21] M. Lewis, "Governance and Corruption in Public Health Care Systems”, SSRN Journal, 2006, doi: 10.2139/ssrn.984046.

[22] P. Bardhan, «Corruption and Development: A Review of Issues», Journal of Economic Literature, vol. 35, no 3, p. 1320-1346, 1997. 
[23] A. Shleifer et R. W. Vishny, "Corruption", The Quarterly Journal of Economics, vol. 108, no 3, p. 599-617, 1993, doi: $10.2307 / 2118402$.

[24] G. Charreaux, "For "behavioural" corporate governance. An exploratory reflection... French Management Journal, 31, 157, 215-238, Jul. 2005, doi: 10.3166/rfg.157.215-238.

[25] B. Coriat and O. Weinstein, "The firm's theories between "contracts" and "skills." A Critical Review of Contemporary Developments, Industrial Economics Review, 129-130, 57-86, June 2010, doi: 10.4000/rei.4142.

[26] Presidency of the Republic of Benin, "The Government's Programme of Actions." March 2017, Consulted: August 22, 2020. [Online]. Available on: http://revealingbenin.com/wpcontent/uploads/2017/03/Le-Programme-dActions.pdf.

[27] Edgard-Marius D. OUENDO and al., "Universal Coverage in French-speaking Africa: Towards the Learning Organization." March 27, 2017, Consulted: August 22, 2020. [online]. Available on: http://www.healthfinancingafrica.org/uploads/8/0/8/8/8088846 /votre_syste\%CC\% $\% 0$ me_csu_est_il_apprenant_rapport_benin .pdf.

[28] «Rapid Assessment of the Health System in Benin, April 2006», SAGE Publications, Inc., 2455 Teller Road, Thousand Oaks California 91320 United States, 2011. doi: 10.4135/9781412994064.n303.

[29] Abt Associates Inc, "SHOPS Project. 2013. Benin Private Health Sector Assessment. Brief. Bethesda, MD: Strengthening Health Outcomes through the Private Sector Project, Abt Associates Inc", Benin, sept. 2013. Consulté le: août 22, 2020. [online]. Available on: https://www.abtassociates.com/sites/default/files/migrated_file s/5009aaae-6662-434a-aad1-7a5934f0eb9b.pdf.

[30] S. J. Adanmavokin, S. G. Armand, I. B. Charlemagne, et O. Edgard-Marius, «Application of the WHO Method of Workload Indicators of Staffing Needs to Evaluate Health
Workers Availability and Capacity for Universal Health Coverage in Maternal and Child Health in Benin», Universal Journal of Public Health, vol. 8, ${ }^{\circ} 5$, p. 163-178, sept. 2020, doi: 10.13189/ujph.2020.080502.

[31] B. HOUNKPATIN, "Breaking Year 4: Health Sector Benjamin HOUNKPATIN Unveils the New Face of the Health Sector," Apr. 24, 2019.

[32] T. Benmarhnia and D. Fuller, "Quasi-Experimental Methods," in Evaluation of Global Health Interventions, Science and Common Good Editions and IRD Editions, 2019.

[33] INSAE, MPD, "Population," Statistics for the Nation, 2020. https://www.insae-bj.org/statistiques/indicateurs-recents/43population (consulted August 24, 2020).

[34] Treasury Board of Canada Secretariat, "Data Assessment and Development Strategic Policy Human Resources Development Canada." Feb 25, 2010, Consulted: August 21, 2020. [Online]. Available on: https://www.tbssct.gc.ca/cee/pubs/meth/pem-mep-fra.pdf.

[35] MoH, "Sanitary Statistics 2019" Yearbook. Ministry of Health, March 2020, [Online]. Available on: www.sante.gouv.bj.

[36] Presidency of the Republic of Benin, "Law 97-020 of June 17, 1997," General Secretariat of the Government of Benin, June 17, 1997. https://sgg.gouv.bj/doc/loi-97-020/ (consulted August 26, 2020).

[37] Presidency of the Republic of Benin, "Decree No. 2018-342 of July 25, 2018," General Secretariat of the Government of Benin, J. D. 25, 2018. https://sgg.gouv.bj/doc/decret-2018342/ (consulted August 22, 2020).

[38] G. Vincent, "Hospital Reforms," French Public Administration Review, No. 113, No. 1, 49-63, 2005.

[39] M. Hensher and N. Edwards, "The hospital of the future: Hospital provision, activity, and productivity in England since the 1980 s", $B M J$, vol. $319, \mathrm{n}^{\circ} 7214$, p. 911-914, oct. 1999, doi: 10.1136/bmj.319.7214.911. 